\title{
Analysis on Influence Factors of Longitudinal Deformation of Metro
}

\section{Shield Tunnel}

\author{
Lixin $\mathrm{Li}^{1, \mathrm{a}}$, Fang Zhao ${ }^{2, \mathrm{~b}^{*}}$ \\ ${ }^{1,2}$ School of Civil Engineering,Shenyang Jianzhu University,Shenyang 110168,China \\ alilixin1966@163.com, ${ }^{b} z$ haofang0405@163.com \\ ${ }^{*}$ Corresponding author
}

Keywords:longitudinal deformation; shield tunnel;soil settlement;deformation control

Abstract:It will seriously affect the safety of tunnel structure if tunnel occurs longitudinal deformation. This paper is based on the shield-driven tunnel, discusses the factors may cause longitudinal deformation of metro tunnel and carries on the concrete analysis during construction period to operation period to the entire time as the research background. The conclusions has guiding significance for the control of longitudinal deformation.

\section{Introduction}

At present, there are many researches about the shield tunnel structure and environmental issues caused by the construction of shield tunnel at home and abroad, most of which are about the horizontal lining structure, the cross-sectional settling tank, the surface longitudinal settlement curve, the influence of the tunnel on the adjacent structures and so on. But there is less study of influence on the longitudinal deformation of tunnel structure.Compared with the mechanical properties of tunnel structure in the transverse direction, the mechanical properties in the longitudinal direction is obviously fragile. Segment ring is tightened by earth pressure and ground reaction pressure around the tunnel lining in the transverse direction. Stability and safety in the transverse direction are guaranteed as soon as the segment ring isn't broken firstly and has not joint crack affecting waterproof. However, longitudinal strain is bad to structure. When the longitudinal deformation and the deformation curvature have reached a certain value, the tunnel would appear leaks because of the circular seam opening or have the segment broken for the axial tension. Oversize longitudinal inhomogeneous deformation of shield tunnel would make too much longitudinal height difference of tunnel, cause the height difference and smoothness over standard, and then influence the safety operation of the train.

\section{Analyze factors influencing the longitudinal deformation of shield tunnel}

Factors influencing the longitudinal deformation of shield tunnel are very complex. Fig. 1 is Shenyang subway during shield tunnel construction land and the typical settlement curve of the tunnel.It shows that settlements of the ground and tunnel have a big difference in the same time after the construction completed. The settlement evolution of lining rings being buried can be divided into three periods according to the principle of temporal sequence and the reasons: 
(1). The period of the initial settlement;

(2). The period of consolidation settlement caused by the delayed dissipation of excess pore water pressure in underlying soft formation;

(3). The period of secondary consolidation settlement caused by the long-time compressive deformation of skeleton in underlying soft formation;

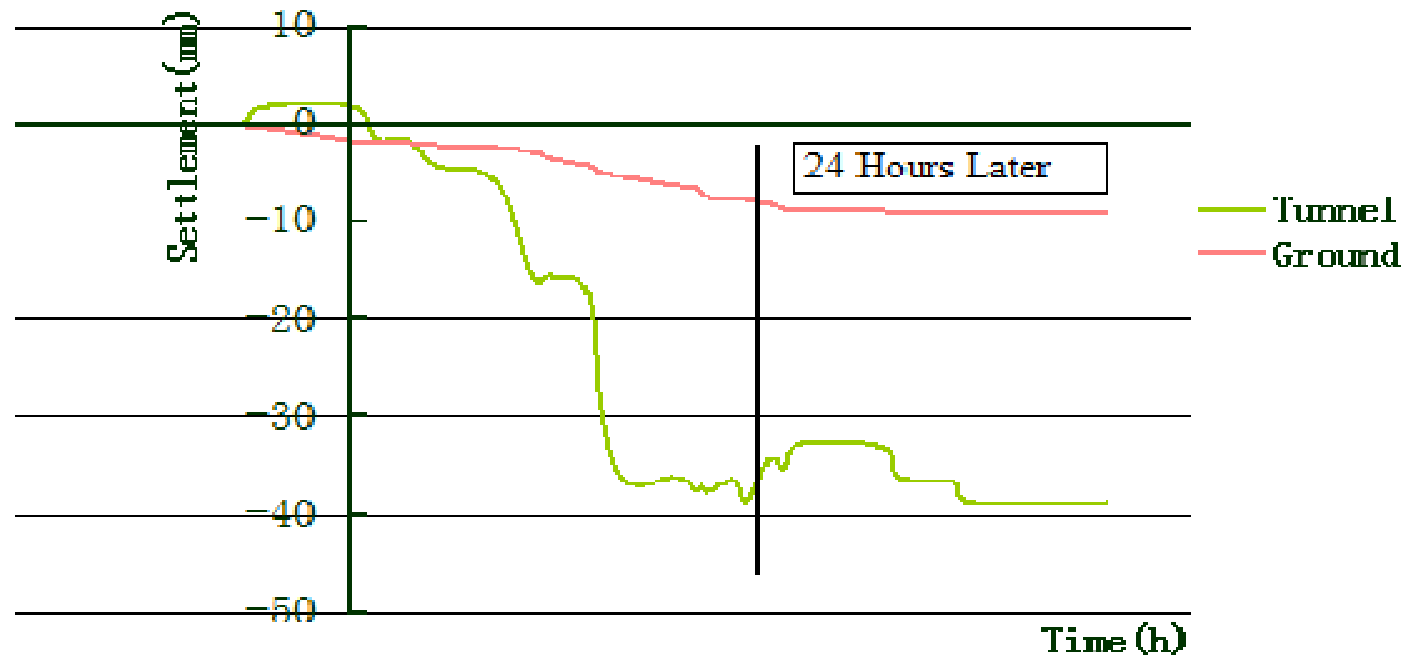

Fig.1 Shenyang subway during shield tunnel construction land and the typical settlement curve of the tunnel

Tunnel is come into use during six months to one year after shield machine moving forward. The initial settlement and the consolidation settlement have been completed before connecting bolt is prepared for the second tighten, while the secondary consolidation settlement is happened slowly in the long-time service stage of the shield tunnel.

the influence factors of longitudinal deformation of shield tunnel during the construction period

1. 1 The disturbance of underlying stratum coming from the driving of shield machine

Fig. 2 shows the soil disturbance schematic during the process of shield machine driving.It mainly comes from the following several factors:

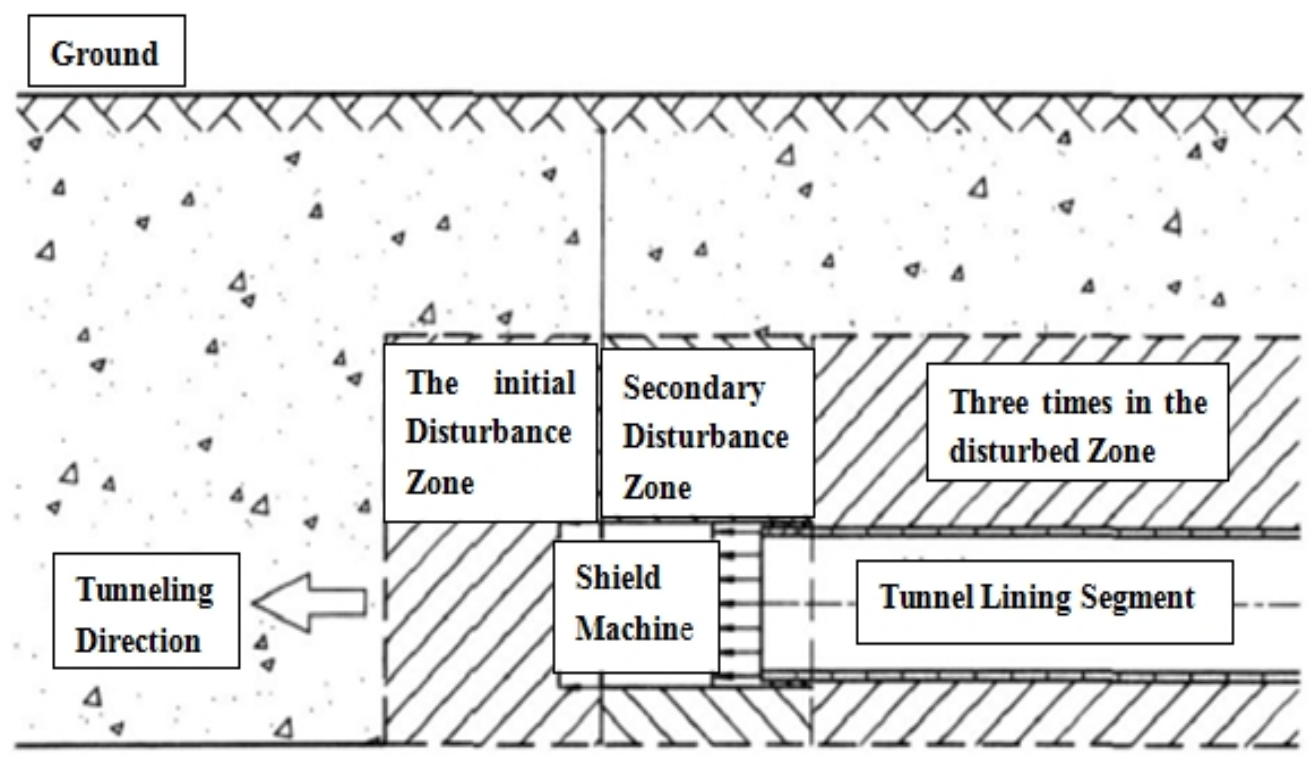

Fig.2 Soil disturbance schematic diagram 
(1). The soil disturbance under the excavation face;

(2). The overbreak caused by the shield machine moving in the orientation of curves and rectification;

(3). The delayed or insufficiency grouting behind the end of shield machine;

(4). The soil disturbance caused by the shield machine extruding and moving;

(5). The soil disturbance around the tunnel caused by the shield machine shell rubbing and shearing the surrounding soil;

The inhomogeneity of underlying formation

With the construction disturbance, the different nature of underlying formation has differences in various degrees in the disturbance, the recurrent magnitude, the reconsolidation of the settlement, settlement velocity and total settling time, and so on. The uneven trait and layering of the soil of underlying formation lead to differential settlement of tunnel along longitudinal direction.

\section{The influence factors of longitudinal deformation of shield tunnel during the operation period}

The different characteristics of secondary consolidation of underlying stratum

Fig. 3 shows longitudinal settlement typical curve of the ground above shield tunnel in different soil conditions. The different nature of soil has a huge difference of consolidation settlement and needs different time for the settlement stability, which causes tunnel to be differential settlement because of uneven distributed soil in the longitudinal direction.

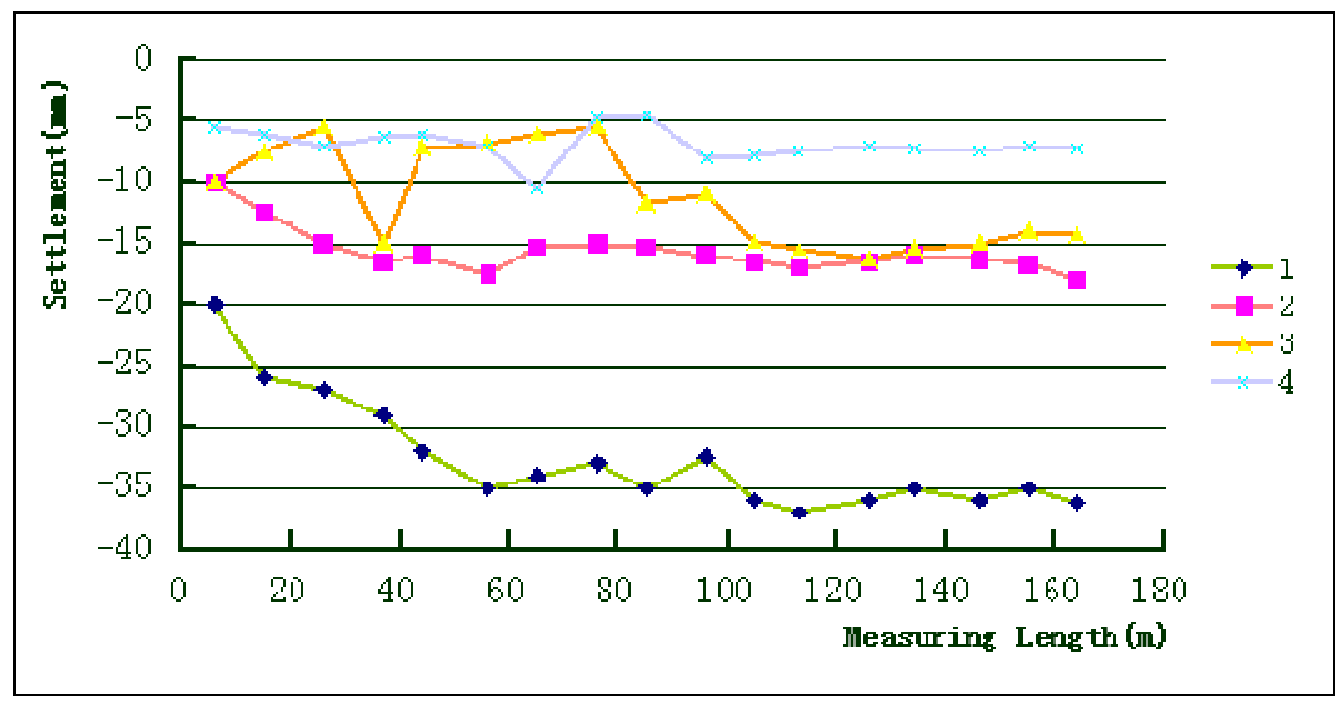

1-Drainage tunnel in Bangkok,soft clay.

2-Metro LRT extension line in Edmonton,Canada,sandy soil containing gravel.

3-Subway tunnel EIK. to Sanit.in Cairo,Egypt,dense sandy silt.

4-Metro DLR extension line in London,clay mixed with silt.

Fig.3 Longitudinal settlement typical curve of the ground above shield tunnel in different soil conditions

The change of water table

The change of water table makes the change of tunnel loading and then leads to differential settlement in the longitudinal direction. To shield tunnel in underwater, the fluctuation of water level above tunnel can influence the settlement of tunnel.

The influence of construction activities adjacent to tunnel (such as the excavation of deep foundation pit, upper-crossing tunnel, undercrossing tunnel and so on ) 
The construction activities are carried out adjacent to the current tunnel, break soil's original stress equilibrium, and make soil displacement around the tunnel, all of which lead to the tunnel uneven strain in the longitudinal direction.

The ground loading above tunnel

When tunnel has the ground loading above it, especially large-area ground loading, the settlement will be increased significantly and the part or whole tunnel will sink.

The differential settlements between the junctions the junction of regional tunnel and station and the junction of regional tunnel and working well

The construction method and reinforcement measure of regional tunnel and station show great differences with these of regional tunnel and working well, which easily produces differential settlements between the junction of regional tunnel and station and the junction of regional tunnel and working well.

The disturbance of train vibration load

With the long-time train vibration load, the underlying formation of tunnel has the possibility of liquefaction and settlement, which has a large influence on the uneven strain of tunnel in the longitudinal direction. If the natural period of oscillation of tunnel structure is same or similar to the vibration period of train loading, the tunnel will carry out the sympathetic vibration and then the longitudinal deformation of the tunnel will be more serious.

The destructive longitudinal deformation caused by soil and water loss of underlying formation of regional tunnel

If there are cracks on the tunnel structure, mud water infiltrate into the tunnel through these cracks, which makes the tunnel with cracks increase effective stress of soil underlying it and produce consolidation settlement in order to the tunnel settlement.

Earthquake action

The acting mechanism and structural response of earthquake are extremely complex. Due to the differences in geological environment, the bending axis of tunnel, the influence of adjacent construction, the different constraints around tunnel and others factors, regional tunnel makes a different reaction to earthquake wave, which leads to uneven strain of tunnel in a longitudinal direction.

\section{Conclusions}

On the background of subway's whole time from construction period to traffic-operating period, the paper discusses various factors that may cause the longitudinal deformation of subway tunnel. From this paper, I can draw several conclusions:

(1). The longitudinal deformation of a section of subway tunnel is usually not only the role of single force but also caused by several factors;

Among these forces, some are relatively minor while some can be prevented by reasonable measures. The main affecting factors are identified by the actual situation and then the corresponding preventative and administrative measures are taken to ensure the safety of subway tunnel.

These conclusions further deepen the understanding of factors of vertical deformation, provides a reference for designers, builders and managers and have a guiding significance for controlling the longitudinal deformation of shield tunnel. 


\section{Acknowledgements}

This project is supported by the Natural Science Foundation of Liaoning Province(Grant No.201202178).

\section{References}

[1] Hongwei Huang,Xiaolong Zang.Analysis on longitudinal deformation behavior of shield tunnel[J].Underground Space,2002,22(3):244-251.(in Chinese)

[2] K.Kimura,Dangerous Gap between Theory and Practice in Earth Pressure Balance Shield Tunneling in Japan[J]. Modern Tunneling Science and Technology, Vol12,LTA,2001 pp.613 -618.

[3] Zhenxing He,Wanming Zhai,Zhen Luo.Ground vibrations caused by the subway train[J].Journal of Southwest Jiaotong University,43(2):218-221.(in Chinese)

[4] Guangyun Gao,Meng Gao,Chengbin Yang,et al.Influence of deep excavation on deformation of operating metro tunnels and measures[J].Chinese Journal of Geotechnical Engineering,2010,32(3):454-459.(in Chinese)

[5] Shaoming Liao, Yanhui Bai,Fangle Peng,et al.Longitudinal settlement forms and structural response of shield tunnel[J].Chinese Journal of Underground Space and Engineering,2006,2(5):765-774.(in Chinese)

[6] Kurzweil G. Ground borne Noise and Vibration from Underground Rail System[J].Journal of Sound and Vibration,1979, Vol.66(3):363 - 370.

[7] Weining Liu,He Xia,Wengun Guo.The environment response of subway train vibrations[J].Chinese Journal of Rock Mechanics and Engineering,1996,15(Supp):586-593.(in Chinese)

[8] Yonglai Zheng,Jie Pan,Wenxing Han.Analysis on the settlements of metro tunnels in soft soil[J].Chinese Journal of Underground Space and Engineering,2005,1(1):68-74.(in Chinese)

[9] Shirlaw J N. Observed and Calculated Pore Pressures and Deformations Induced by an Earth Balance Shield Discussion[J].Canadian Geotechnical Journal.1995,(32):181-189. 